\title{
Identification of Missense Mutation (I12T) in the BSND Gene and Bioinformatics Analysis
}

\author{
Hina Iqbal, ${ }^{1}$ Tayyba Sarfaraz, ${ }^{2}$ Farida Anjum, ${ }^{3}$ Zubair Anwar, ${ }^{1}$ and Asif Mir ${ }^{1}$ \\ ${ }^{1}$ Department of Bioinformatics and Biotechnology, International Islamic University, Islamabad 44000, Pakistan \\ ${ }^{2}$ Department of Biosciences, COMSATS Institute of Information Technology, Islamabad 44000, Pakistan \\ ${ }^{3}$ Research and Development Section, Higher Education Commission, Islamabad 44000, Pakistan
}

Correspondence should be addressed to Asif Mir, mir77uspk@yahoo.com

Received 20 October 2010; Revised 21 December 2010; Accepted 4 February 2011

Academic Editor: Susan Blanton

Copyright (C) 2011 Hina Iqbal et al. This is an open access article distributed under the Creative Commons Attribution License, which permits unrestricted use, distribution, and reproduction in any medium, provided the original work is properly cited.

\begin{abstract}
Nonsyndromic hearing loss is a paradigm of genetic heterogeneity with 85 loci and 39 nuclear disease genes reported so far. Mutations of BSND have been shown to cause Bartter syndrome type IV, characterized by significant renal abnormalities and deafness and nonsyndromic nearing loss. We studied a Pakistani consanguineous family. Clinical examinations of affected individuals did not reveal the presence of any associated signs, which are hallmarks of the Bartter syndrome type IV. Linkage analysis identified an area of $18.36 \mathrm{Mb}$ shared by all affected individuals between markers D1S2706 and D1S1596. A maximum two-point LOD score of 2.55 with markers D1S2700 and multipoint LOD score of 3.42 with marker D1S1661 were obtained. BSND mutation, that is, p.I12T, cosegregated in all extant members of our pedigree. BSND mutations can cause nonsyndromic hearing loss, and it is a second report for this mutation. The respected protein, that is, BSND, was first modeled, and then, the identified mutation was further analyzed by using different bioinformatics tools; finally, this protein and its mutant was docked with CLCNKB and REN, interactions of BSND, respectively.
\end{abstract}

\section{Introduction}

Deafness or hearing loss can be due to genetic or environmental causes or a combination of both. The genetic hearing loss is classified as syndromic or nonsyndromic. Among the many disorders classified as syndromic hearing loss, the pathology varies widely, but in nonsyndromic hearing loss, the defect is generally sensorineural. Seventy percent of deafness has genetic causes and is classified as nonsyndromic. Autosomal recessive nonsyndromic deafness is genetically heterogeneous and is the most common form of inherited hearing loss. Autosomal recessive genes are responsible for about $77 \%$ of the cases of hereditary nonsyndromic deafness, with over 85 loci and 21 different genes identified to date (http://hereditaryhearingloss.org/). The high degree of genetic heterogeneity of deafness reflects the great diversity of specialized proteins that are required to make sense of sound, and continuing discovery of common and rare mutations associated with deafness in humans has provided many serendipitous points of entry into the biology of hearing.

Bartter's syndrome (BS) is characterized by hypokalemic, hypochloremic metabolic alkalosis with normal or low blood pressure despite high plasma renin activity and serum aldosterone. The inheritance pattern is autosomal recessive. Antenatal BS with bilateral sensorineural deafness (BSND) was first described in children born to a consanguineous couple from a Bedouin family of Southern Israel [1]. BS type IV, BSND variant, occurs because of a mutation in the BSND gene on chromosome $1 \mathrm{p} 31$ coding for protein "barttin" which forms the $\beta$ subunit of CICKb and CICKa channels located on the basolateral membrane of TAL and inner ear epithelium [2]. The clinical features of Bartter syndrome type IV include sensorineural deafness and peculiar facies, distinguished by the triangular face, large eyes, and protruding ears (1).

Mutation in BSND gene is analyzed by model prediction using SAM_T08 server. Comparison of the protein sequence 
of BSND with closely related species takes place and find out conserved regions. Other bioinformatics analysis such as protein modeling and proteins docking are also carried out for more bioinformation.

\section{Materials and Methods}

Before the onset of the study, approval from the Institutional Review Board, Islamabad, and informed consent was obtained from all individuals. Clinical examination was performed at hospitals of the respective area. Audiometry was performed on selected individuals to detect the level of hearing loss. The families were visited at their places of residence to generate pedigrees [3] and collect other relevant information. Blood samples from available affected and normal individuals of each family were collected for DNA extraction.

2.1. Genotyping and Linkage Studies. High molecular weight DNA was extracted from leukocytes following the standard method as described by Sambrook et al. [4]. Genomic DNA was quantified by spectrophotometer readings at $\mathrm{OD}_{260}$ and diluted to $40 \mathrm{ng} / \mathrm{uL}$ for amplification by polymerase chain reaction (PCR).

To elucidate the gene defect in the family presented here, an initial search for linkage was carried out by using polymorphic microsatellite markers mapped within autosomal recessive nonsyndromic deafness loci listed on the hereditary hearing loss homepage [5]. Genome-wide screening was conducted with microsatellite markers (Linkage Mapping Set 10, Invitrogen, USA). Two-point linkage analysis was carried out using MLINK of the FASTLINK computer package [6]. Multipoint linkage analysis was performed using ALLEGRO [7]. For the analysis, an autosomal recessive mode of inheritance with complete penetrance and a disease allele frequency of 0.001 were assumed. Equal allele frequencies were used in the analysis. However, since it is well known that using allele frequencies, which are too low, can lead to false positive results, a sensitivity analysis was performed. Haplotypes were constructed using SIMWALK2 $[8,9]$.

2.2. Mutation Screening. To screen for mutation in the BSND gene, exons and splice junction sites were PCR amplified from genomic DNA using the four primer sets. The purified PCR products were subjected to cycle sequencing using big dye terminator $\mathrm{V} 3.1$ ready reaction mix and sequencing buffer (PE Applied Biosystems, Foster City, Calif, USA). The sequencing products were purified to remove unincorporated nucleotides and primers with Centriflex TM Gel Filtration Cartridge (Edge Biosystems, Gaithersburg, Md, USA). These purified products were resuspended in $10 \mu \mathrm{L}$ of TSR (Template Suppression Reagent) and were placed in $0.5 \mathrm{~mL}$ septa tubes to be directly sequenced in an ABI Prism 310 Automated Sequencer (PE Applied Biosystems, Foster City, Calif, USA). Chromatograms from normal and affected individuals were compared with the corresponding control gene sequences from NCBI (National Center for Biotechnology Information) database to identify the aberrant nucleotide base-pair change. (http://www.ncbi.nlm.nih.gov/).
2.3. Protein Modeling, Docking, and Phylogenetics Analysis. SAM_T08 [10-14] was used to model the BSND protein and its interacting protein with highest confidence score (i.e., 0.990) CLCNKB. For their further evaluation, RAMPAGE server [15] was considered. ClustalW program was subjected to analyze the phylogenetics relationship of different animals having BSND protein. Conserved amino acids were predicted by using UniportKB tool available on Expasy server.

Identified BSND mutation was generated by using Swisspdb server. Protein interactor of BSND was found out by STRING server, an online database of known and predicted protein interactions which includes direct (physical) and indirect (functional) associations [16]. Protein docking of both the normal and the mutant BSND was carried out using HEX tool with its interactive proteins CLCNKB and REN.

\section{Results}

3.1. Clinical Assessments. Ages of affected individuals varied between 12 and 65 years at the time of study. Clinical examination of the hearing impaired individuals did not reveal the presence of signs or symptoms, which are hallmarks of the Bartter syndrome type IV. Urinary and blood biochemistry was tested at the Islamabad Diagnostic Centre, including testing for liver function, renal function, electrolytes, and hematology. Blood hematology and biochemistry markers were within the normal range, except that renin level was at borderline in one of the affected subject (VI: $5,2.53 \mathrm{~mL} / \mathrm{h}$ ). Detailed clinical and biochemical features of normal and affected members are mentioned in Table 1 . The height and weight were within normal range for the local population. An audiometric evaluation of selected affected members by measuring the threshold of hearing at $250-8000 \mathrm{~Hz}$ for puretune air conduction and bone conduction showed severe hearing loss across all frequencies.

Renal sonography ruled out the presence of nephrocalcinosis or metabolic alkalosis in these affected individuals. Nor have the affected individuals displayed problems with polydipsia, polyuria, nocturnal enuresis, and hypocalciuria.

3.2. Genotyping Results. Analysis of the results obtained from genome search performed on the ten individuals of the family (III-1, III-3, IV-1, V-1, V-2, V-4, V-5, VI-1, VI-3, and VI-5) (Figure 1) identified an area of interest on chromosome 1. Two-point analysis generated LOD score of 2.027 at marker D1S193 $(73.21 \mathrm{~cm})$ and 2.05 at marker D1S3462 $(247.23 \mathrm{~cm})$ on chromosome 1 (Table 2). In order to test linkage to these two regions, additional markers located in the vicinity of D1S3462 and D1S193 were chosen from Marshfield map [17] and genotyped in all the ten family members. The maximum two-point LOD score was increased to 2.55 with marker D1S2700. Multipoint linkage analysis for the family derived a maximum LOD score of 3.42 at marker D1S1661 (Table 3). The three-unit multipoint support interval contained a $10.48 \mathrm{Mb}$ region, which span from markers D1S3721 to D1S2690. Haplotypes analysis delimited the centromeric boundary defined by a recombination between markers D1S1596 and D1S2770 
TABLE 1: Clinical and biochemical features of normal and affected members of studied family.

\begin{tabular}{|c|c|c|c|c|c|c|}
\hline \multirow{2}{*}{ Features } & \multirow{2}{*}{ Reference ranges } & \multicolumn{2}{|c|}{ Normal members } & \multicolumn{3}{|c|}{ Affected members from the family with hearing loss } \\
\hline & & $\mathrm{V}: 3$ & $\mathrm{~V}: 5$ & $\mathrm{~V}: 1$ & $\mathrm{VI}: 3$ & $\mathrm{VI}: 5$ \\
\hline Age $(y)$ & & 30 & 35 & 45 & 12 & 10 \\
\hline Other symptoms of BSIV & & no & no & No & No & No \\
\hline $\mathrm{S}^{\mathrm{d}} \cdot \mathrm{Na}(\mathrm{mmol} / \mathrm{L})$ & $136-148$ & 141 & 140 & 135 & 137 & 134 \\
\hline $\mathrm{S} \cdot \mathrm{K}(\mathrm{mmol} / \mathrm{L})$ & $3.6-5.0$ & 3.9 & 4.6 & 3.4 & 3.5 & 3.5 \\
\hline $\mathrm{S} \cdot \mathrm{Cl}(\mathrm{mmol} / \mathrm{L})$ & $104-114$ & 105 & 107 & 97 & 102 & 101 \\
\hline $\mathrm{S} \cdot \mathrm{Mg}(\mathrm{mg} / \mathrm{dl})$ & $1.9-2.5$ & 2.3 & 2.2 & 2.0 & 1.9 & 2.1 \\
\hline $\mathrm{s} \cdot \mathrm{HCO} 3(\mathrm{mmol} / \mathrm{L})$ & $17.5-27.5$ & 30.0 & 27.5 & 30.0 & 30.2 & 31.0 \\
\hline $\mathrm{S} \cdot \mathrm{Ca}(\mathrm{mg} / \mathrm{dl})$ & $8.6-10.5$ & 8.7 & 9.5 & 9.2 & 9.8 & 10.0 \\
\hline $\mathrm{S} \cdot$ Creatinine $(\mathrm{mg} / \mathrm{dL})$ & $0.85-1.35$ & 0.7 & 0.8 & 0.6 & 0.5 & 0.4 \\
\hline $\mathrm{P}^{\mathrm{e}} \operatorname{Renin}(\mathrm{ng} / \mathrm{ml} / \mathrm{hr})$ & $0.15-2.33$ & 0.31 & 0.6 & 2.13 & 2.03 & 2.53 \\
\hline S. Aldosterone (ng/dL) & $1-6 ;^{\mathrm{f}} 4-31$ & $>1.7^{\mathrm{f}}$ & 13.0 & 10.3 & 11.9 & 6.3 \\
\hline S. Osmolality (mosm $/ \mathrm{kg})$ & $275-295$ & 293 & 289 & 281 & 290 & 287 \\
\hline $\mathrm{U}^{\mathrm{g}} \mathrm{Na}(\mathrm{mmol} / \mathrm{L})$ & $30-150$ & 17.5 & 154.6 & 39.1 & 16.9 & 13.3 \\
\hline $\mathrm{U} \cdot \mathrm{K}(\mathrm{mmol} / \mathrm{L})$ & $20-67$ & 3.4 & 91.31 & 12.13 & 8.43 & 4.12 \\
\hline $\mathrm{U} \cdot \mathrm{Ca}(\mathrm{mg} / \mathrm{dL})$ & & 6.0 & 16.0 & 15.3 & 11.3 & 13.0 \\
\hline $\mathrm{U} \cdot \mathrm{Mg}(\mathrm{mg} / \mathrm{dL})$ & & 3.6 & 14.4 & 3.1 & 2.4 & 1.12 \\
\hline $\mathrm{U} \cdot \mathrm{Cl}(\mathrm{mmol} / \mathrm{L})$ & $46-168$ & 16.3 & 174.3 & 46.56 & 19.2 & 10.5 \\
\hline Uosmolality (mosm/kg) & $50-1400$ & 74 & 903 & 179 & 105 & 56 \\
\hline NephrocacinosisS & & Absent & Absent & Absent & Absent & Absent \\
\hline
\end{tabular}

in individual V-1. Recombination event between D1S2706 and D1S3721, defined the telomeric boundary in the same individual (V-1). Therefore, the minimum critical region of $18.36 \mathrm{Mb}$ identified for disease locus and shared by all the affected individuals between the markers D1S2706 and D1S1596. The critical interval $(17.27 \mathrm{~cm})$ identified in this Pakistani family overlaps with the critical region to which DFNA2 was mapped on 1p34 in a large Indonesian family with autosomal dominant, progressive and sensorineural hearing loss [18]. The DFNA2 locus maps between markers D1S255 $(65.47 \mathrm{~cm})$ and D1S211 $(73.81 \mathrm{~cm})$, and thus shares a region of $2.68 \mathrm{~cm}$ with DFNB interval identified in our family. Riazuddin et al. [19] identified $1.5 \mathrm{Mb}$ in four kindred segregating nonsyndromic deafness at the chromosome 1.

3.3. Mutation Analysis of Candidate Genes. Through a database search, we identified several genes mapping between the linkage interval in the family (Human Genome Project-Santa Cruz; http://genome.ucsc.edu/, May 2004). Among these, KCNQ4 (MIM 603537), CLDN19, FOXE3 (MIM 601094), FOXD2 (MIM 602211), TSPAN1, and BSND (MIM 606412) were plausible candidate candidates in the interval of our family. We started sequencing of these and completely sequenced two genes (KCNQ4 and CLDIN19), but we found no mutation in both. Recent studies of Riazuddin et al. [19] showed that mutation in BSND can cause nonsyndromic deafness and is the molecular basis of
DFNB73 locus in four Pakistani families segregating nonsyndromic deafness [19]. As the critical interval identified in the family contains potential candidate gene barttin (BSND, MIM 606412) as well; therefore, it was sequenced to search for the mutation. Sequence analysis of exon 1 of the BSND gene in our family also revealed missense mutation involving $\mathrm{T}$ to $\mathrm{C}$ transition at nucleotide number $35(35 \mathrm{~T}>\mathrm{C})$, which resulted in substitution of isoleucine to threonine at amino acid position 12 (I12T) (Figure 2). BSND mutation; that is, p.I12T cosegregated in all extant members of the pedigree. This mutation was present in the heterozygous state in obligate carriers within the family.

3.4. Bioinformatics Analysis. Models of BSND CLCNKB and REN proteins were generated by SAM_T08 server and visualized by Rasmol (Figure 3(a)-3(c)). Rampage values for BSND were number of residues in favored region $95.6 \%$, the number of residues in allowed region $3.1 \%$, and the number of residues in outlier region $1.4 \%$ (Figure 4(a)); however, the CLCNKB and REN values were little varying. Its values were the number of residues in favored region: $94.8 \%, 97 \%$, the number of residues in allowed region: $4.2 \%, 3 \%$, and the number of residues in outlier region is $0.9 \%$ for CLCNKB and $0 \%$ for REN (Figure 4(c)).

Comparison of conserved amino acid of human BSND with closely related species like mouse, rat, and rabbit shows that isoleucine at position 12 is highly conserved, so 
D1S472 $65.47 \mathrm{cM}$

D1S186 $67.22 \mathrm{cM}$

D1S432 69.86cM

D1S1598 70.41cM

D1S2706 71.13cM

D1S3721 72.59cM

D1S193 $73.21 \mathrm{cM}$

D1S2713 73.81cM

D1S2134 75.66cM

DiS1661 78.25cM

D1S2652 80.77cM

D152690 $83.07 \mathrm{cM}$

D1S2700 $87.31 \mathrm{cM}$

DIS2770 $88.40 \mathrm{cM}$

D1S1596 89.49cM

D1S2737 $90.58 \mathrm{cM}$

D1S2788 $93.86 \mathrm{cM}$

DIS230 $95.31 \mathrm{cM}$

D1S1648 $101.48 \mathrm{cM}$

D1S1665 $102.02 \mathrm{cM}$

D1S472 $65.47 \mathrm{cM}$

\begin{tabular}{lll} 
D1S186 & $67.22 \mathrm{cM}$ \\
\hline 15432 & $69.86 \mathrm{cM}$
\end{tabular}

D1S432 69.86cM

D1S1598 $70.41 \mathrm{cM}$

D1S2706 71.13cM

DIS3721 72.59cM

DIS2713 73.81cM

DiS2713 73.81cM

D1S1661 78.25cM

DIS $265280.77 \mathrm{cM}$

DiS2690 83.07cM

DIS2700 87.31cM

D1S2770 88.40cM

DIS1596 89.49c

D1S2737 90.58cM

D1S2788 $93.86 \mathrm{cM}$

DIS230 $95.31 \mathrm{cM}$

D1S1648 $101.48 \mathrm{cM}$

D1S1665 $102.02 \mathrm{cM}$

D1S472 $65.47 \mathrm{cM}$

D1S186 $67.22 \mathrm{cM}$

D1S432 69.86cM

DIS1598 70.41cM

D1S2706 71.13cM

DIS3721 $72.59 \mathrm{cM}$

D1S193 73.21cM

DIS2713 73.81cM

DIS2134 75.66cM

D1S1661 78.25cM

DIS2652 80.77cM

DIS2690 83.07cM

D1S2700 87.31cM

DIS2770 88.40cM

DIS1596 89.4cM

D1S2788 $93.86 \mathrm{cM}$

D1S230 $95.86 \mathrm{cM}$

D1S1648 $101.48 \mathrm{cM}$

DiS1665 $102.02 \mathrm{cM}$
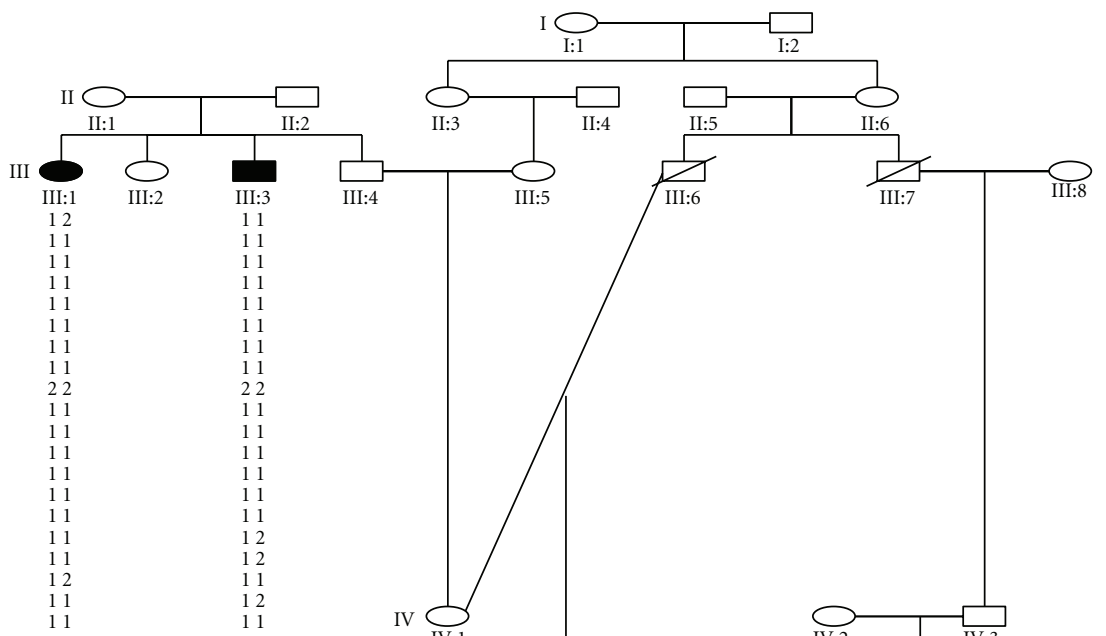

D1S472 $65.47 \mathrm{cM}$

D1S186 $67.22 \mathrm{cM}$

D1S432 69.86cM

D1S1598 70.41cM

D1S2706 71.13cM

D1S3721 72.59cM

D1S193 $73.21 \mathrm{cM}$

D1S2713 73.81cM

D1S2134 75.66cM

D1S1661 78.25cM

D1S2652 $80.77 \mathrm{cM}$

D1S2690 83.07cM

D1S2700 $87.31 \mathrm{cM}$

D1S2770 88.40cM

D1S1596 89.49cM

D1S2737 90.58cM

D1S2788 93.86cM

D1S230 $95.31 \mathrm{cM}$

D1S1648 101.48cM

D1S1665 $102.02 \mathrm{cM}$

FIGURE 1: Pedigree of family with nonsyndromic autosomal recessive hearing loss associated haplotypes. Haplotypes for the most closely linked STRPs are shown below each symbol. The genetic map distances according to the Marshfield genetic map in centimorgans (cM) are shown in parenthesis next to the marker name. Arrows adjacent to the haplotypes indicate key recombination events. The alleles are denoted $1-3$ according to their allele size. 
TABLe 2: Two-point LOD score results between the locus identified in family and chromosome 1p34.2-p32.1 markers.

\begin{tabular}{|c|c|c|c|c|c|c|c|c|c|}
\hline \multirow{2}{*}{ Marker } & \multirow{2}{*}{ deCode map postion ${ }^{1}$} & \multirow{2}{*}{ Marshfield map postion ${ }^{2}$} & \multirow{2}{*}{ Physical map postion ${ }^{3}$} & \multicolumn{6}{|c|}{ LOD score AT $\theta=$} \\
\hline & & & & 0.00 & 0.01 & 0.05 & 0.1 & 0.2 & 0.3 \\
\hline D1S472 & 57.95 & 65.47 & $37,102,828$ & -999.99 & -0.68 & -0.05 & 0.14 & 0.20 & 0.13 \\
\hline D1S186 & 60.14 & 67.22 & $37,900,316$ & -999.99 & -.069 & -0.10 & 0.05 & 0.10 & 0.06 \\
\hline D1S432 & - & 69.86 & $39,046,164$ & -1.334 & -0.69 & -0.18 & -0.02 & 0.03 & 0.01 \\
\hline D1S1598 & 63.51 & 70.41 & $40,011,183$ & -1.544 & -0.61 & -0.09 & 0.03 & 0.04 & 0.00 \\
\hline D1S2706 & 65.31 & 71.13 & $40,741,361$ & -999.99 & -1.34 & -0.18 & 015 & 0.24 & 0.14 \\
\hline D1S3721 & 65.87 & 72.59 & $41,395,560$ & 2.027 & 1.97 & 1.75 & 1.49 & 1.49 & 0.56 \\
\hline D1S193 & 66.64 & 73.21 & $42,688,369$ & 2.027 & 1.97 & 1.75 & 1.49 & 0.99 & 0.56 \\
\hline D1S2713 & 67.87 & 73.81 & $44,182,569$ & 1.726 & 1.67 & 1.47 & 1.24 & 0.80 & 0.43 \\
\hline D1S2134 & 71.29 & 75.66 & $47,993,241$ & 1.690 & 1.66 & 1.52 & 1.32 & 0.91 & 0.52 \\
\hline D1S1661 & 72.42 & 78.25 & $51,142,551$ & 1.228 & 1.19 & 1.06 & 0.90 & 0.60 & 0.33 \\
\hline D1S2652 & 77.15 & 80.77 & $55,178,852$ & 1.319 & 1.28 & 1.13 & 0.96 & 0.62 & 0.34 \\
\hline D1S2690 & 79.63 & 83.07 & $56,867,560$ & 2.027 & 1.97 & 1.75 & 1.49 & 0.99 & 0.56 \\
\hline D1S2700 & 83.07 & 87.31 & $58,828,955$ & 2.556 & 2.48 & 2.21 & 1.88 & 1.23 & 0.66 \\
\hline D1S2770 & 85.02 & 88.40 & $59,442,255$ & -999.99 & -0.26 & 0.26 & 0.35 & 0.29 & 0.17 \\
\hline D1S1596 & - & 89.49 & $59,670,589$ & -1.55 & -0.52 & -0.00 & 0.10 & 0.08 & 0.01 \\
\hline D1S2737 & 85.47 & 90.58 & $61,038,037$ & -999.99 & -1.10 & 0.07 & 0.40 & 0.46 & 0.29 \\
\hline D1S2788 & 87.25 & 93.86 & $61,568,857$ & -999.99 & -2.16 & -0.90 & -0.46 & -0.14 & -0.03 \\
\hline D1S230 & 88.12 & 95.31 & $62,314,306$ & -999.99 & -2.16 & -0.90 & -0.46 & -0.14 & -0.03 \\
\hline D1S1648 & 99.62 & 101.48 & $73,125,563$ & -999.99 & -2.27 & -1.00 & -0.55 & -0.20 & -0.06 \\
\hline D1S1665 & 99.62 & 102.02 & $73,941,402$ & -999.99 & -2.34 & -1.04 & -0.57 & -0.20 & -0.06 \\
\hline
\end{tabular}

${ }^{1}$ Sex-average Kosambi cM map distances from the deCode genetic map [7].

${ }^{2}$ Sex-average Kosambi cM map distances from the Marshfield genetic map [17].

${ }^{3}$ Sequence-based physical map distance in bases according to the Human Genome Project-Santa Cruz (http://genome.ucsc.edu/, Assembly: May 2004).

TABLE 3: Multipoint LOD score results between linked locus identified in family and chromosome 1p34.2-p32.1 markers.

\begin{tabular}{lccc}
\hline Marker & Physical position & Location & LOD \\
\hline ATA79C10 & - & 0.0000 & -2.0630 \\
D1S472 & $37,102,828$ & 3.0940 & nan \\
D1S186 & $37,900,316$ & 5.1350 & nan \\
D1S432 & $39,046,164$ & 8.2290 & -2.4708 \\
D1S1598 & $40,011,183$ & 9.2390 & -0.0755 \\
D1S2706 & $\mathbf{4 0 , 7 4 1 , 3 6 1}$ & $\mathbf{1 0 . 2 4 9 0}$ & $-\mathbf{8 . 2 1 0 3}$ \\
D1S3721 & $41,395,560$ & 11.2590 & 3.0063 \\
D1S193 & $42,688,369$ & 12.2690 & 3.2113 \\
D1S2713 & $44,182,569$ & 14.3100 & 3.3672 \\
D1S2134 & $47,993,241$ & 16.3510 & 3.4190 \\
D1S1661 & $51,142,551$ & 18.3920 & 3.4201 \\
D1S2652 & $55,178,852$ & 21.4860 & 3.3868 \\
D1S2690 & $56,867,560$ & 24.5800 & 3.2867 \\
D1S2700 & $58,828,955$ & 28.7490 & 2.8398 \\
D1S2770 & $59,442,255$ & 29.7590 & 1.3404 \\
D1S1596 & $\mathbf{5 9 , 6 7 0 , 5 8 9}$ & $\mathbf{3 0 . 7 6 9 0}$ & nan \\
D1S2737 & $61,038,037$ & 31.7800 & - inf \\
D1S2788 & $61,568,857$ & 34.8730 & nan \\
D1S230 & $62,314,306$ & 36.9140 & - inf \\
D1S1648 & $73,125,563$ & 43.3060 & - inf \\
D1S1665 & $73,941,402$ & 44.3160 & nan \\
GATA152F05L & $85,238,770$ & 45.3260 & nan \\
\hline
\end{tabular}

mutation at this point can be significant (Figure 5(a)). The evolutionary relationship between human, mouse, rat, and rabbit were evaluated by phylogenetic analysis. The analysis represents that the BSND of mouse and rat is closely related to each other and shows homology with human and rabbit (Figure 5(b)).

Our mutation (I12T) of BSND was generated by Swisspdb server and was analyzed by Viewerlite. This substitution of isoleucine with threonine altered the bonding capacity with other side chains as well as other interactors (Figure $6(\mathrm{a})-(\mathrm{b}))$.

According to STRING database, the physical and functional interaction of BSND was very much significant with CLCNKB protein. Clinical assessment showed the reduced chlorine level in all the affected individuals. According to further clinical assessments, renin level was at border range in one affected individual, so REN protein was also selected to check the effect of the respected mutation on this protein. However, other interactors are COL7A1, ARL2, CLCN5, KCNJ1, CASR, SLC12A1, SLC12A3, and CLCNKA (Figure 7). Both the proteins were docked with HEX v 6.1, taking BSND as receptor and CLCNKB and REN as a ligand. The total energy value calculated for BSND-CLCNKB molecules was -229094.6 and BSND-REN was -1145.7. However, the total energy value for the mutant (I12T) on docking with CLCNKB was maximized to -218782.3 and with REN was -1149.8 . This values fluctuation ultimately results in reduced binding affinity with CLCNKB and 


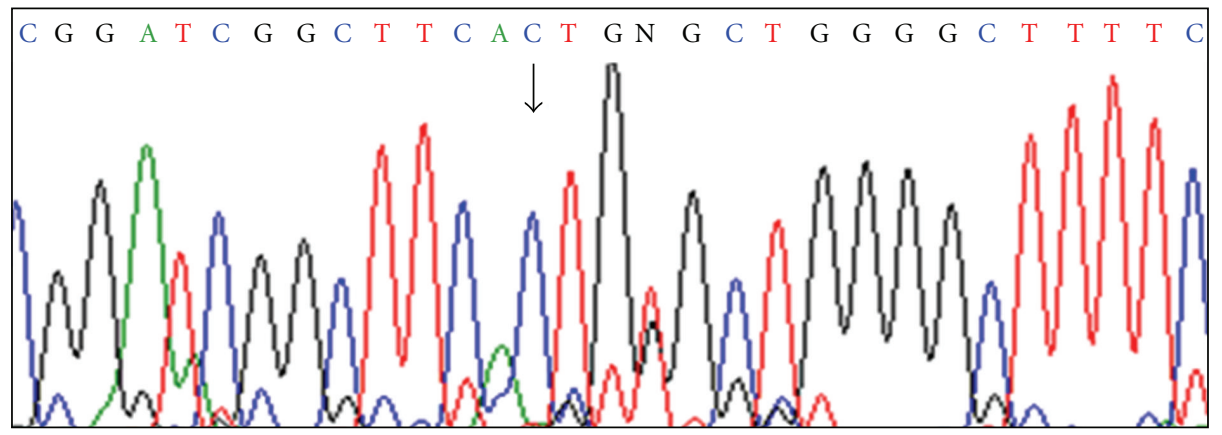

(a)

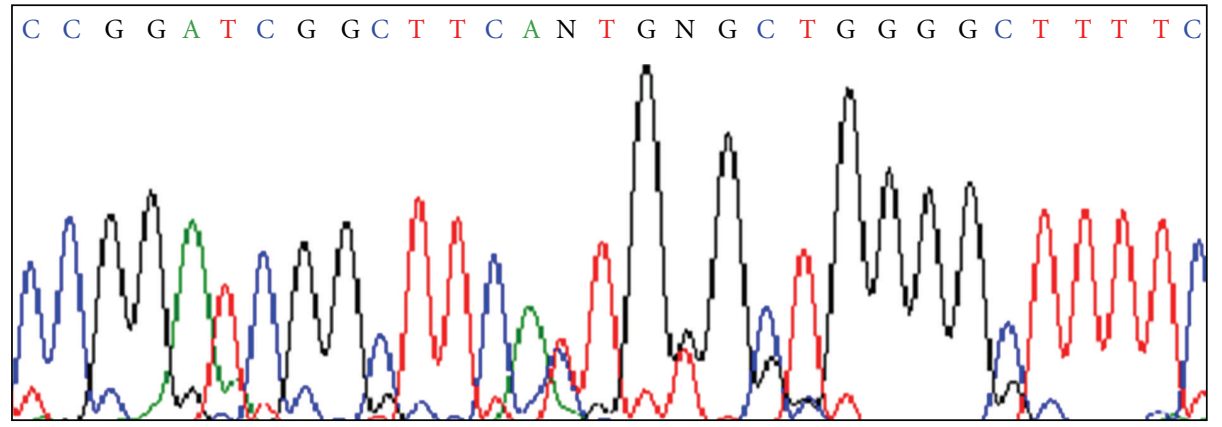

(b)

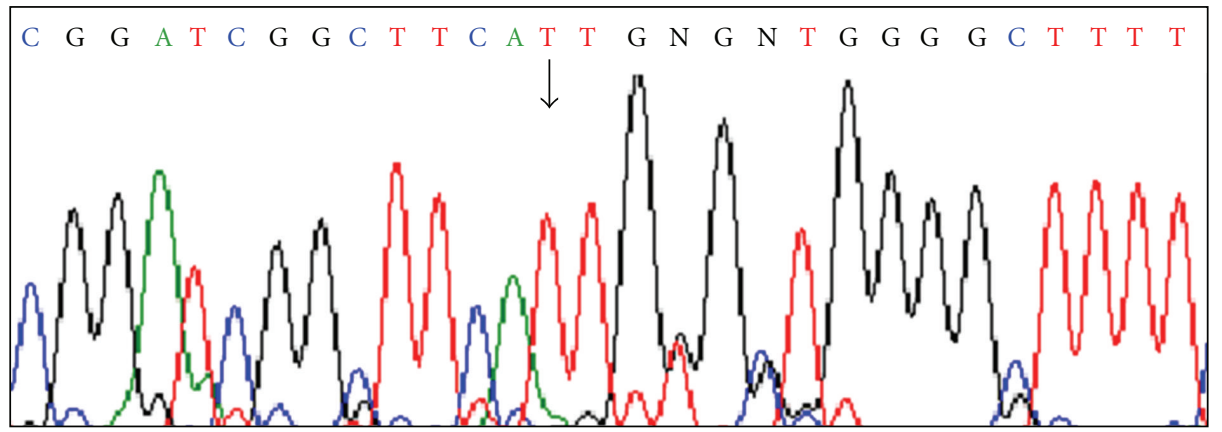

(c)

FIGURE 2: Representative chromatogram generated by Big Dye Terminator, sequencing of translated exon1 of BSND gene indicating a T to $\mathrm{C}$ transition at nucleotide 35 (35T > C) from an affected female individual (VI-1) (a), a heterozygous carrier (VI-1) (b) and a normal male individual (V-2) (c) of the family. The $\mathrm{T}$ to $\mathrm{C}$ transition at nucleotide position 35 results in isoleucine to threonine change at amino acid 12 (I12T). Arrows indicate the nucleotide change in the sequence.

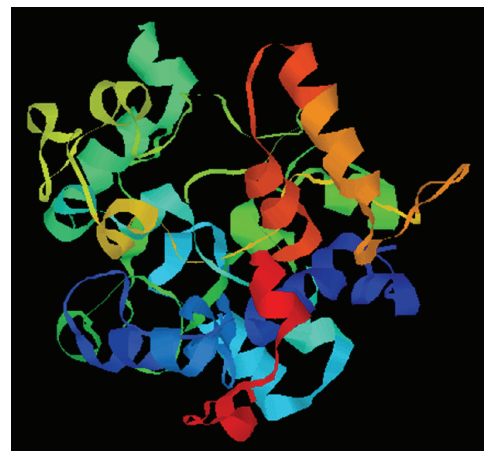

(a)

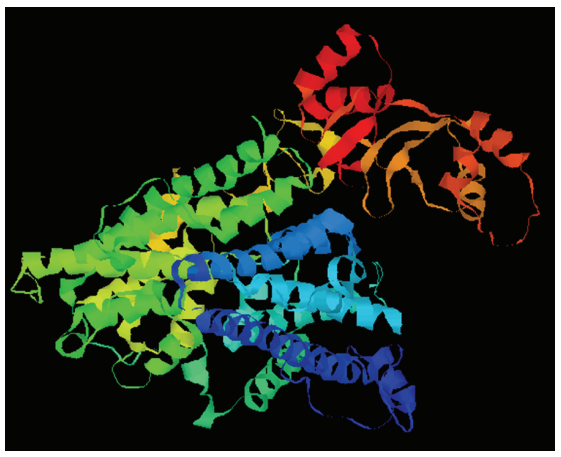

(b)

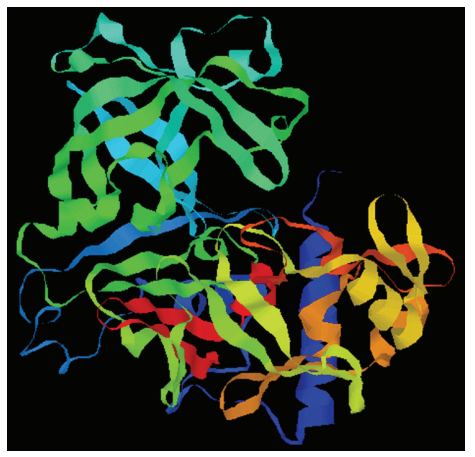

(c)

FIgURE 3: Protein models of BSND (a) CLCNKB (b), and REN (c) generated by SAM_T08 and visualized by Rasmol (display = ribbon; colors = group). 

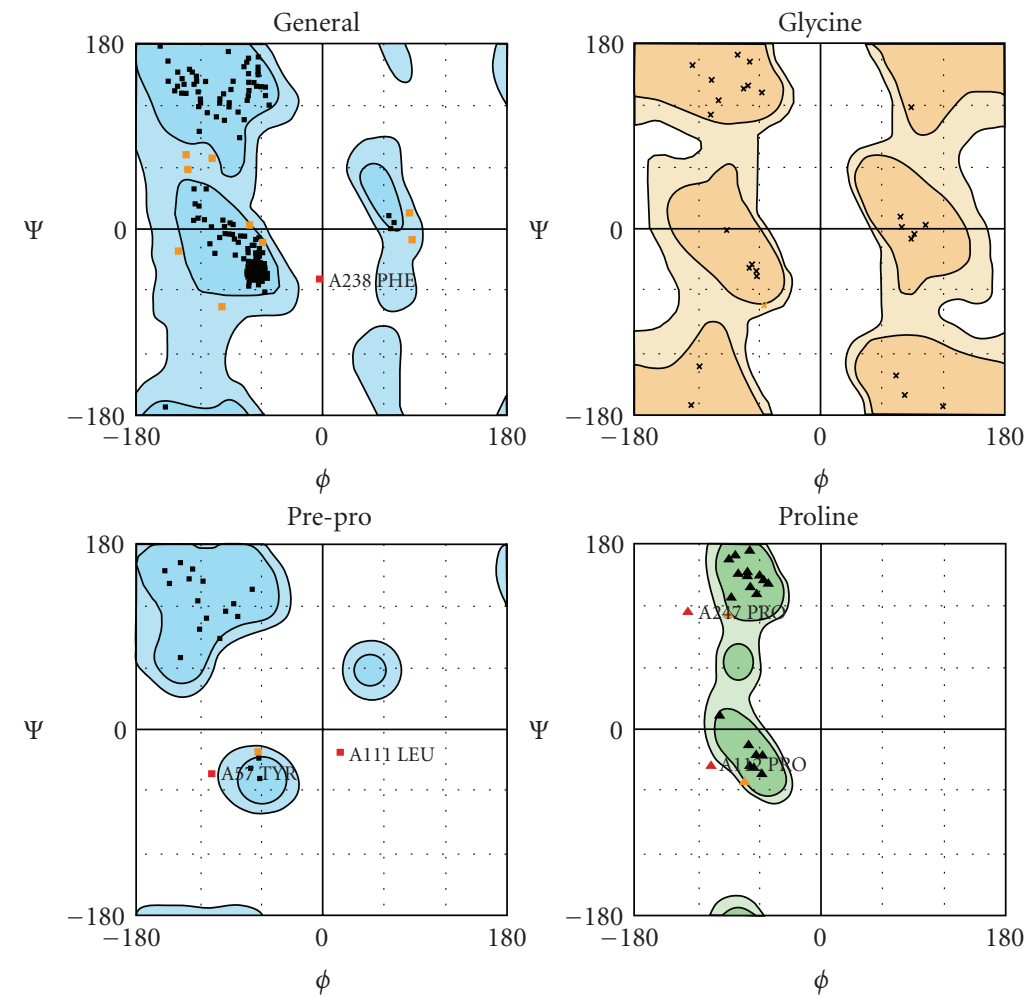

(a)
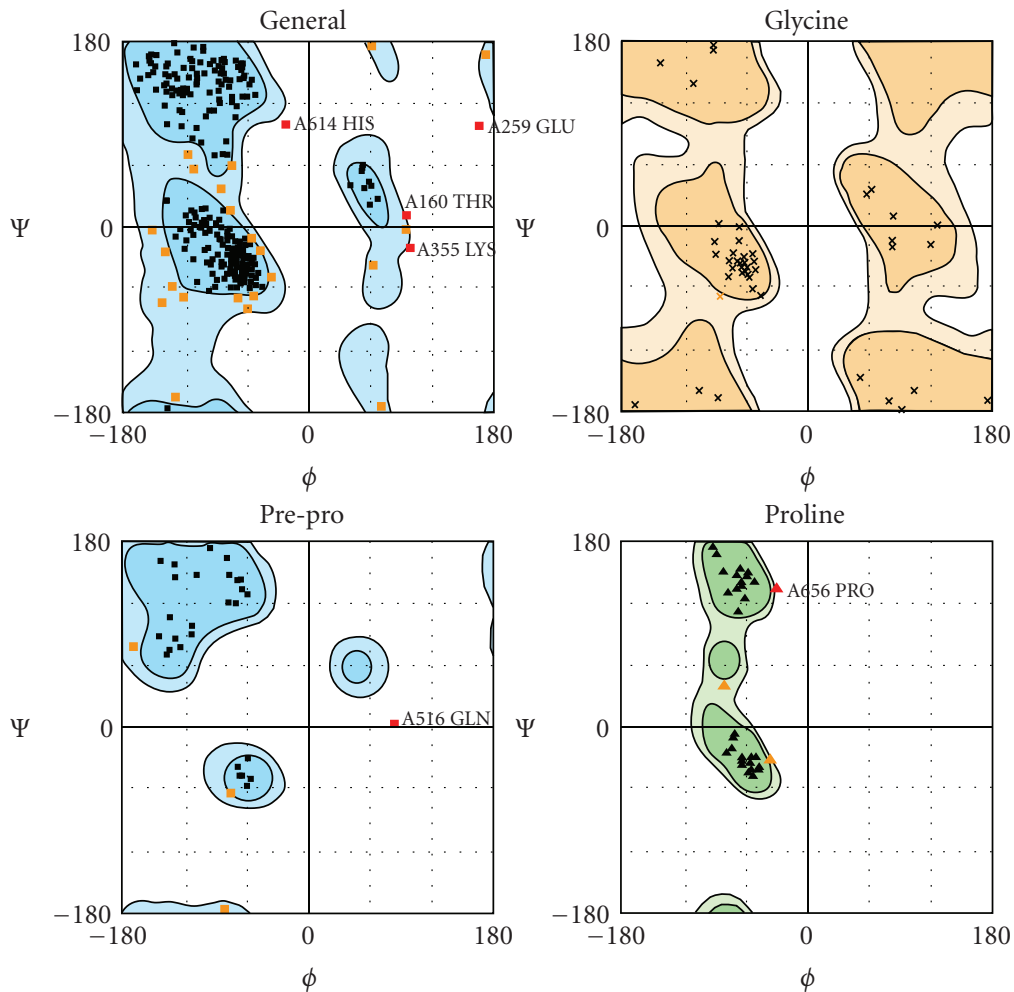

General favoured
Glycine favoured
Pre-pro favoured
Proline favoured

General allowed

Glycine allowed

Pre-pro allowed

Proline allowed

(b)

Figure 4: Continued. 

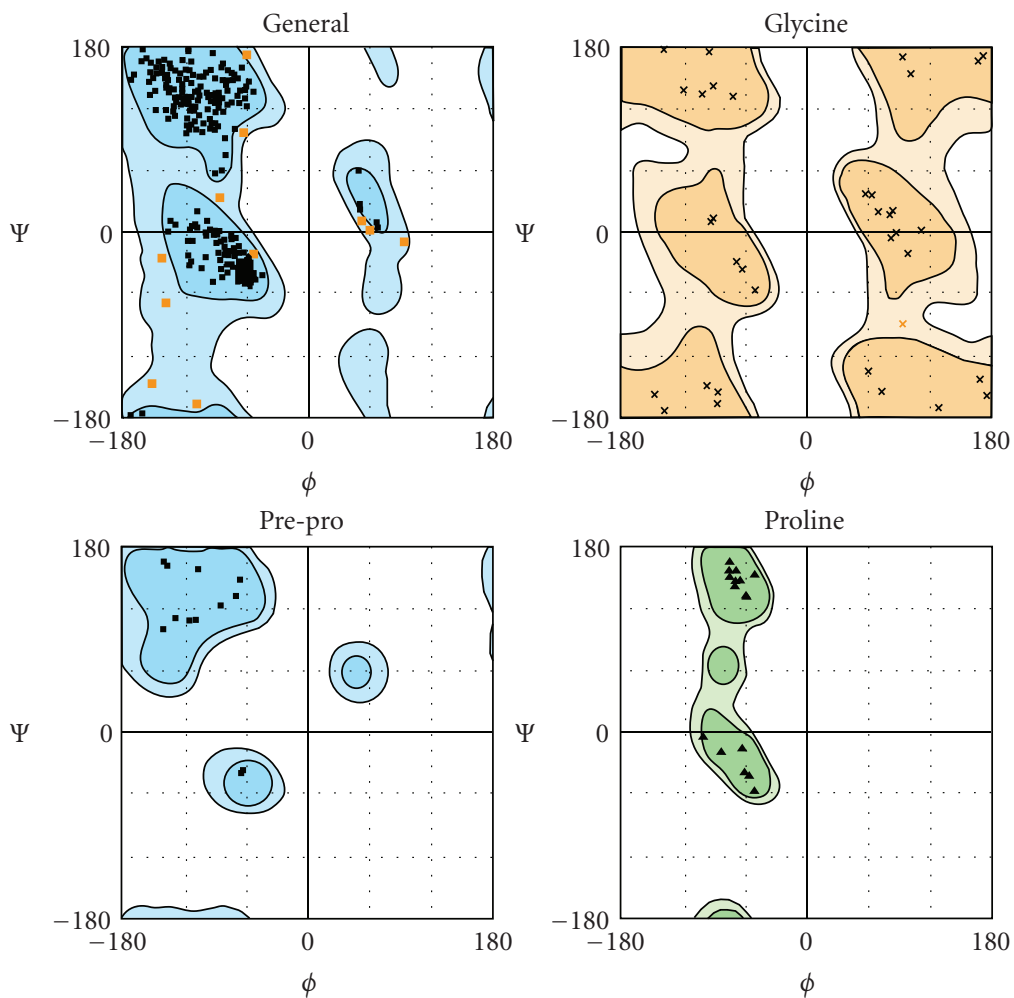

General favoured

Glycine favoured

Pre-pro favoured

Proline favoured

General allowed

Glycine allowed

Pre-pro allowed

Proline allowed

(c)

FIGURE 4: Rampage results of residues for protein model of human BSND protein (a) CLCNKB (b) and REN (c).

increased binding affinity with REN and so may be the case with other interacting proteins.

\section{Discussion}

Pathophysiological pathway leading from a specific mutation to a specific phenotype has remained elusive in syndromic as well as nonsyndromic hearing loss families. Individuals with the same mutation can fall along a clinical spectrum ranging from asymptomatic to severely affected and can even have completely different diseases with different mutation in the same gene. Our results also support the findings of Riazuddin et al. [19] that pathogenic mutation of BSND gene can cause the nonsyndromic hearing loss. But there are no subclinical renal metabolic changes in our family as reported by Riazuddin et al. [19]. Renin level is at boarder range only in one affected individual, while renal sonography ruled out the presence of nephrocalcinosis in these affected individuals. Nor have the affected individuals displayed problems with polydipsia, polyuria, nocturnal enuresis, metabolic alkalosis, and hypocalciuria. It might be possible that partial loss of function of barttin induced by T12I allele cause only selectively hearing loss and appear to have less pronounced effects. However, the genotype does not always predict the clinical phenotype, which varies both within and between families carrying the mutation in the same gene, implying the existence of other genetic and/or environmental factors that influence phenotype. Several disease-causing BSND mutations have been identified and functionally analyzed. In all cases, there is a genotypephenotype relationship in that the level of function of mutant barttin predicts the renal phenotype. Our results support the relationship between missense BSND mutation (I12T) and nonsyndromic hearing loss. It is a secondary report that the BSND as causal gene in nonsyndromic deafness.

The protein sequence of BSND is highly conserved in closely related species of human, mouse, rat, and rabbit, and it contains 2 putative transmembrane domain starting from 7 to 26 amino acid and 31 to 53 amino acid [20].

Bioinformatics analysis of mutation in BSND protein suggest that isoleucine, a hydrophobic amino acid, is being converted into threonine, a polar amino acid, which is more susceptible to posttranslation modifications, affecting the quaternary structure of protein resulting in mutant protein. 


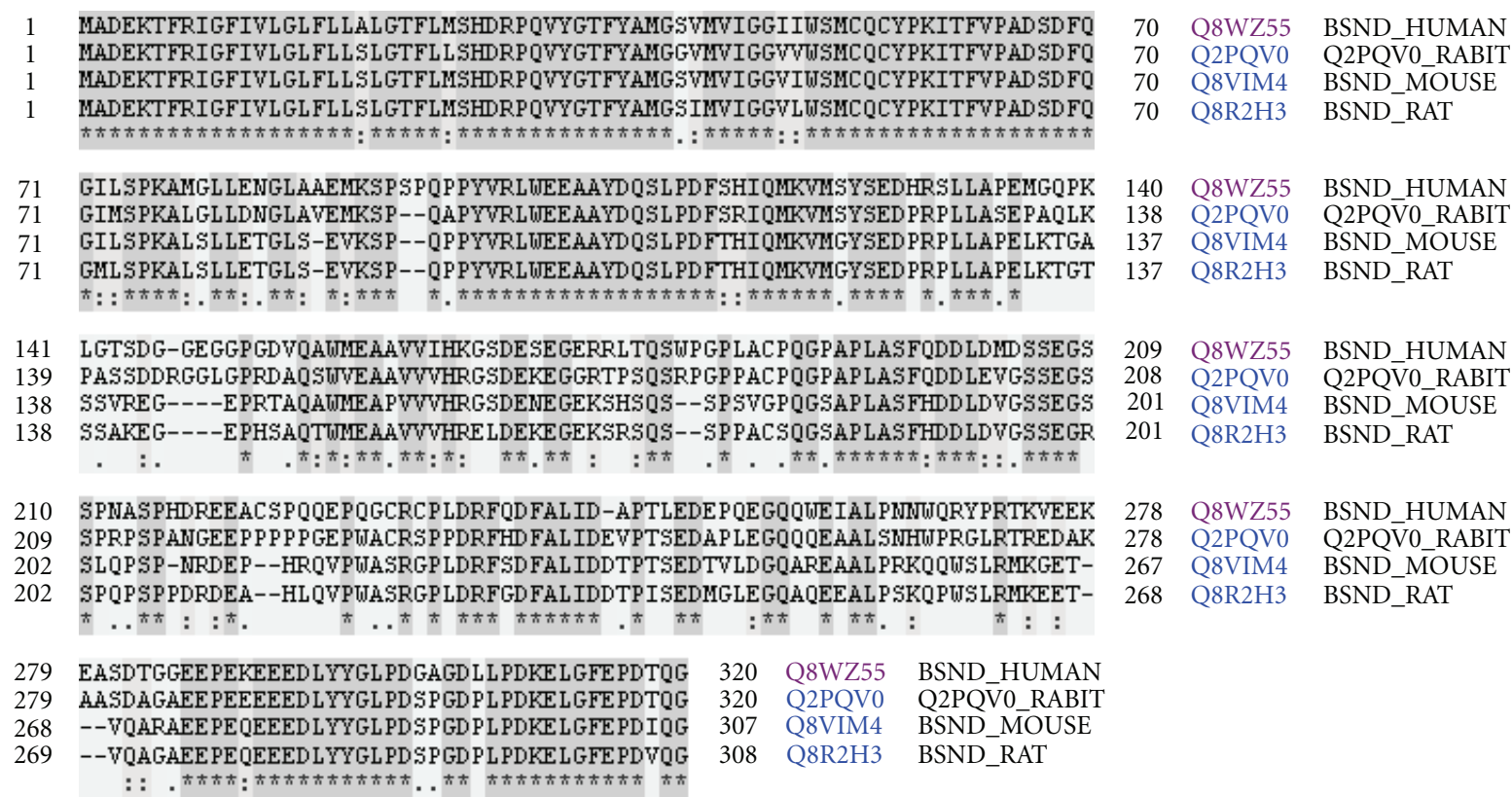

140 Q8WZ55

138 Q2PQV0

137 Q8VIM4

137 Q8R2H3

BSND HUMAN

Q2PQV0 RABIT

BSND_MOUSE

BSND_RAT

209 Q8WZ55

208 Q2PQV0

201 Q8VIM4

201 Q8R2H3

BSND_HUMAN

Q2PQV 0 RABIT

BSND_MOUSE

278 Q8WZ55

278 Q2PQV0

267 Q8VIM4

268 Q8R2H3

BSND_RAT

BSND_HUMAN Q2PQVE_RABIT

BSND MOUSE

BSND_RAT

(a)

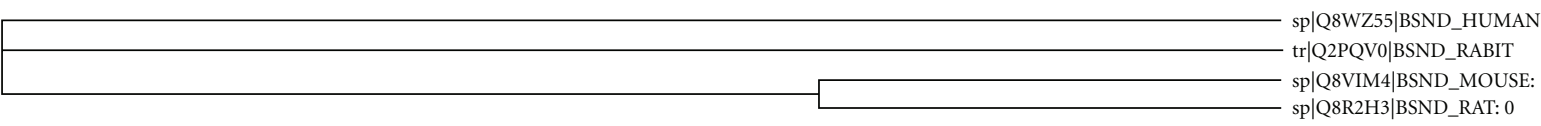

(b)

FIGURE 5: (a) Comparison of conserved regions of BSND protein between human, mouse, rat, and rabbit by using UniportKB ClustalW. Dark region shows conserved amino acid sequence between species. (b) Phylogenetic analysis of BSND protein. It shows evolutionary relationship between human, mouse, rat, and rabbit species.

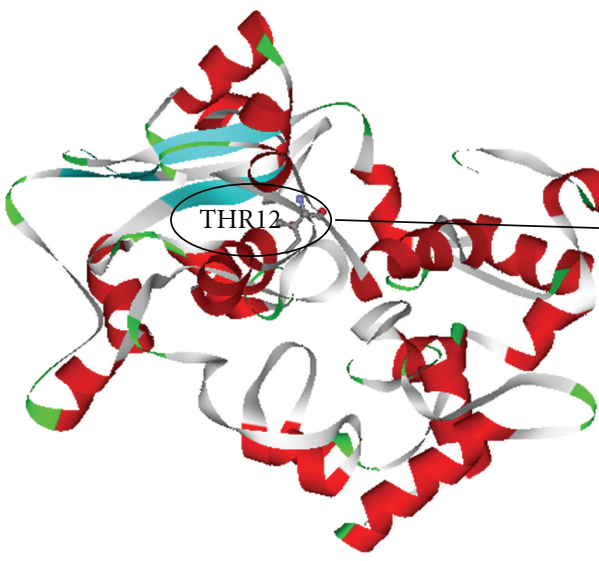

(a)

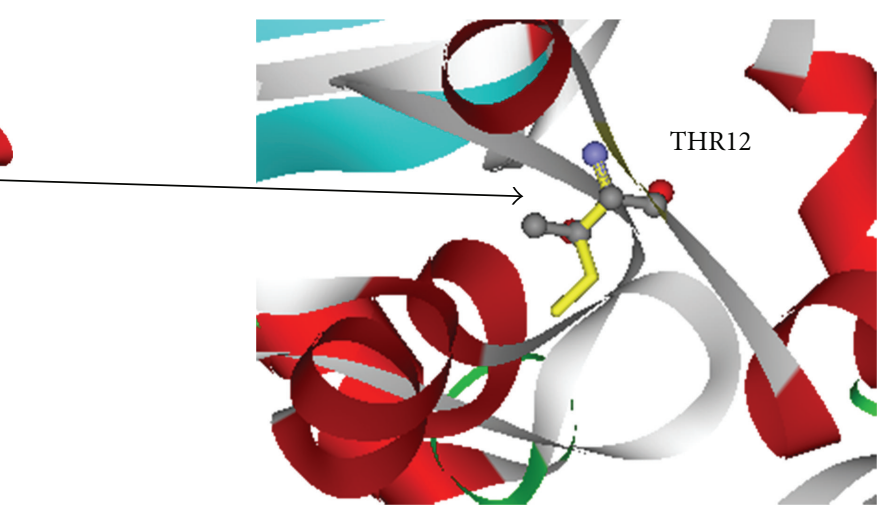

(b)

FIGURE 6: (a) Normal and mutated model (Il12T) of BSND are superimposed and visulized in Viewerlite. (b) Focused normal model is yellow highlighted and displayed in stick format, and mutated is displayed in ball and stick format.

Barttin (BSND) is an accessory subunit that modifies protein stability, subcellular distribution, and voltagedependent gating of $\mathrm{ClC}-\mathrm{K}$ chloride channels expressed in renal and inner ear epithelia. $\mathrm{ClC}-\mathrm{K}$ channels are doublebarreled channels with two identical protopores that may be opened by individual or common gating processes [21].
Potassium $\left(\mathrm{K}^{+}\right)$secretion by strial marginal cells and vestibular dark cells require $\mathrm{Cl}^{-}$to recycle in the basolateral membrane via a major $\mathrm{Cl}^{-}$conductance. This $\mathrm{Cl}^{-}$conductance is composed of the $\mathrm{Cl}^{-}$channels CLCNKA/BSND and CLCNKB/BSND. $\mathrm{Cl}^{-}$channels CLCNKA/BSND and CLCNKB/BSND consist of the pore-forming CLCNKA 


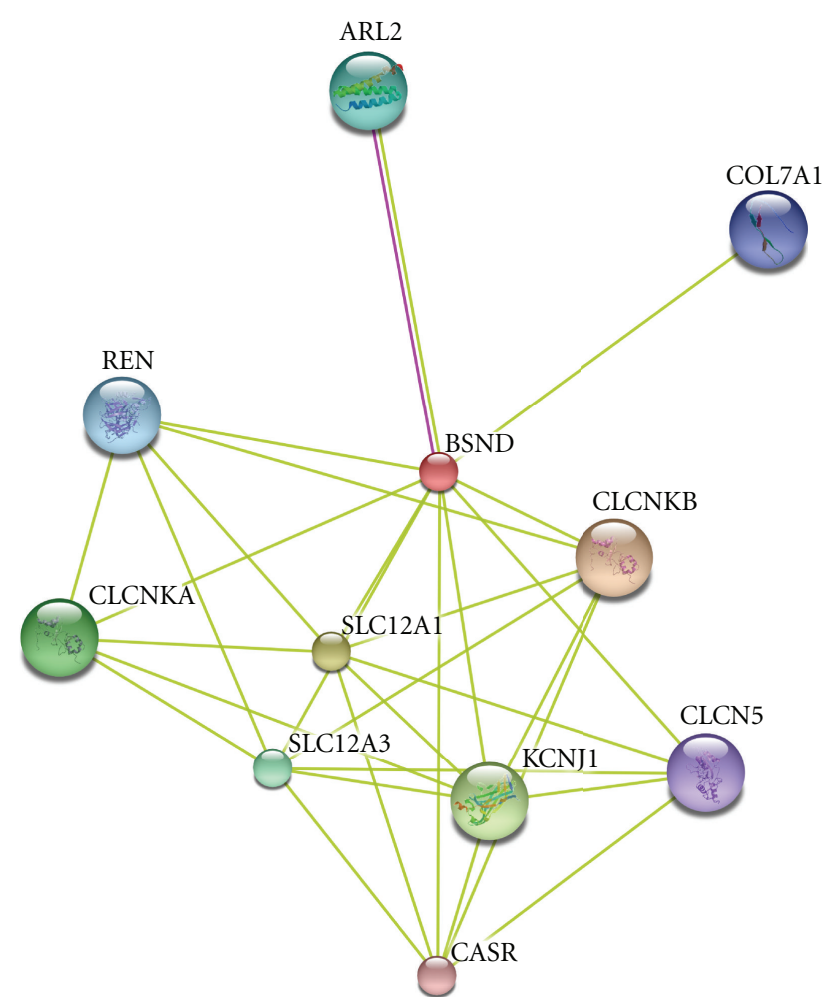

FIGURE 7: The interactions of BSND with other functionally similar proteins retrieved by STRING online database. CLCNKB showed highest confidence score, that is, 0.990 with BSND.

$\alpha$-subunits and CLCNKB and the BSND $\beta$-subunit. Mutations of BSND reduce channel conductivity and surface expression [22].

Estévez et al. [2] proved that BSND protein is an essential $\beta$ subunit for CLCNKA and CLCNKB chloride channels, with which it colocalizes in basolateral membranes of renal tubules and of potassium-secreting epithelia of the inner ear. Disease-causing mutations in either CLCNKB or BSND compromise currents through heteromeric channels [2].

The CLCNKA and CLCNKB channels are members of the ClC family, which comprises at least 9 mammalian chloride channels. Each is believed to have 12 transmembrane domains and intracellular $\mathrm{N}$ and $\mathrm{C}$ termini. The prototype of the family in torpedo is gated by both voltage and chloride [23].

Docking results of both normal and mutant interaction with CLCNKB suggested that there is a reduced binding affinity on mutation which may results the reduced down regulating or up regulating interactions; however, the mutant does not effect the interaction with renin (REN). So, we can conclude that the boarder range of renin level in one affected individual is not dependent upon this mutation.

Identification of mutation in BSND gene in more families will give valuable insight into the genetic mechanisms underlying nonsyndromic hearing disorder. This work is a fundamental step in the bioinformatics analysis of BSND and provides basics for further analysis.

\section{Electronic-Database Information}

(i) Marshfield Medical Research Foundation database website: http://research.marshfieldclinic.org/genetics/.

(ii) National Center for Biotechnology Information: http://www.ncbi.nlm.nih.gov/.

(iii) UCSC Genome Browser: http://genome.ucsc.edu/.

$\begin{array}{ll}\text { Abbreviations } \\ \text { BSND: } & \text { Bilateral sensorineural deafness } \\ \text { CLCNKB: } & \text { Chloride Channel, Kidney, B } \\ \text { REN: } & \text { Renin } \\ \text { ARF: } & \text { ADP-ribosylation factor } \\ \text { I: } & \text { Isoleucine } \\ \text { T: } & \text { Threonine. }\end{array}$

\section{Acknowledgment}

This work was supported by Higher Education Commission (HEC), Islamabad, Pakistan.

\section{References}

[1] D. Landau, H. Shalev, M. Ohaly, and R. Carmi, "Infantile variant of Bartter syndrome and sensorineural deafness: a new autosomal recessive disorder," American Journal of Medical Genetics, vol. 59, no. 4, pp. 454-459, 1995.

[2] R. Estévez, T. Boettger, V. Stein et al., "Barttin is a Cl channel $\beta$-subunit crucial for renal $\mathrm{Cl}$ reabsorption and inner ear $\mathrm{K}+$ secretion," Nature, vol. 414, no. 6863, pp. 558-561, 2001.

[3] R. L. Bennett, K. A. Steinhaus, S. B. Uhrich et al., "Recommendations for standardized human pedigree nomenclature," American Journal of Human Genetics, vol. 56, no. 3, pp. 745752, 1995.

[4] J. Sambrook, E. F. Fritsch, and T. Maniatis, Molecular Cloning: A Laboratory Manual, vol. 1, Cold Spring Harbor Laboratory Press, New York, NY, USA, 2nd edition, 1989.

[5] G. Van Camp and R. J. H. Smith, "Hereditary Hearing Loss Homepage," http://hereditaryhearingloss.org/.

[6] R. W. Cottingham, R. M. Idury, and A. A. Schaffer, "Faster sequential genetic linkage computations," American Journal of Human Genetics, vol. 53, no. 1, pp. 252-263, 1993.

[7] D. F. Gudbjartsson, K. Jonasson, M. L. Frigge, and A. Kong, "Allegro, a new computer program for multipoint linkage analysis," Nature Genetics, vol. 25, no. 1, pp. 12-13, 2000.

[8] D. E. Weeks, E. Sobel, J. R. O’Connell, and K. Lange, "Computer programs for multilocus haplotyping of general pedigrees," American Journal of Human Genetics, vol. 56, no. 6, pp. 1506-1507, 1995.

[9] E. Sobel and K. Lange, "Descent graphs in pedigree analysis: applications to haplotyping, location scores, and markersharing statistics," American Journal of Human Genetics, vol. 58, no. 6, pp. 1323-1337, 1996.

[10] K. Karplus, "SAM-T08, HMM-based protein structure prediction," Nucleic Acids Research, vol. 37, supplement 2, pp. W492W497, 2009. 
[11] S. Katzman, C. Barrett, G. Thiltgen, R. Karchin, and K. Karplus, "Predict-2nd: a tool for generalized protein local structure prediction," Bioinformatics, vol. 24, no. 21, pp. 24532459, 2008.

[12] G. Shackelford and K. Karplus, "Contact prediction using mutual information and neural nets," Proteins: Structure, Function and Genetics, vol. 69, no. 8, pp. 159-164, 2007.

[13] R. Karchin, M. Cline, Y. Mandel-Gutfreund, and K. Karplus, "Hidden Markov models that use predicted local structure for fold recognition: alphabets of backbone geometry," Proteins: Structure, Function and Genetics, vol. 51, no. 4, pp. 504-514, 2003.

[14] K. Karplus, R. Karchin, C. Barrett et al., "What is the value added by human intervention in protein structure prediction?" Proteins: Structure, Function and Genetics, vol. 45, no. 5, pp. 86-91, 2001.

[15] S. C. Lovell, I. W. Davis, W. B. Arendall III et al., "Structure validation by $\mathrm{C} \alpha$ geometry: $\varphi, \psi$ and $\mathrm{C} \beta$ deviation," Proteins: Structure, Function and Genetics, vol. 50, no. 3, pp. 437-450, 2003.

[16] L. J. Jensen, M. Kuhn, M. Stark et al., "STRING 8-a global view on proteins and their functional interactions in 630 organisms," Nucleic Acids Research, vol. 37, no. 1, pp. D412D416, 2009.

[17] K. W. Broman, J. C. Murray, V. C. Sheffield, R. L. White, and J. L. Weber, "Comprehensive human genetic maps: individual and sex-specific variation in recombination," American Journal of Human Genetics, vol. 63, no. 3, pp. 861-869, 1998.

[18] P. Coucke, G. Van Camp, B. Djoyodiharjo et al., "Linkage of autosomal dominant hearing loss to the short arm of chromosome 1 in two families," New England Journal of Medicine, vol. 331, no. 7, pp. 425-431, 1994.

[19] S. Riazuddin, S. Anwar, M. Fischer et al., "Molecular basis of DFNB73: mutations of BSND can cause nonsyndromic deafness or Bartter syndrome," American Journal of Human Genetics, vol. 85, no. 2, pp. 273-280, 2009.

[20] I. Letunic, T. Doerks, and P. Bork, "SMART 6: recent updates and new developments," Nucleic Acids Research, vol. 37, no. 1, pp. D229-D232, 2009.

[21] M. Fischer, A. G. H. Janssen, and C. Fahlke, "Barttin activates CLC-K channel function by modulating gating," Journal of the American Society of Nephrology, vol. 21, no. 8, pp. 1281-1289, 2010.

[22] F. Lang, V. Vallon, M. Knipper, and P. Wangemann, "Functional significance of channels and transporters expressed in the inner ear and kidney," American Journal of Physiology, vol. 293, no. 4, pp. C1187-C1208, 2007.

[23] T. J. Jentsch and W. Günther, "Chloride channels: an emerging molecular picture,” BioEssays, vol. 19, no. 2, pp. 117-126, 1997. 

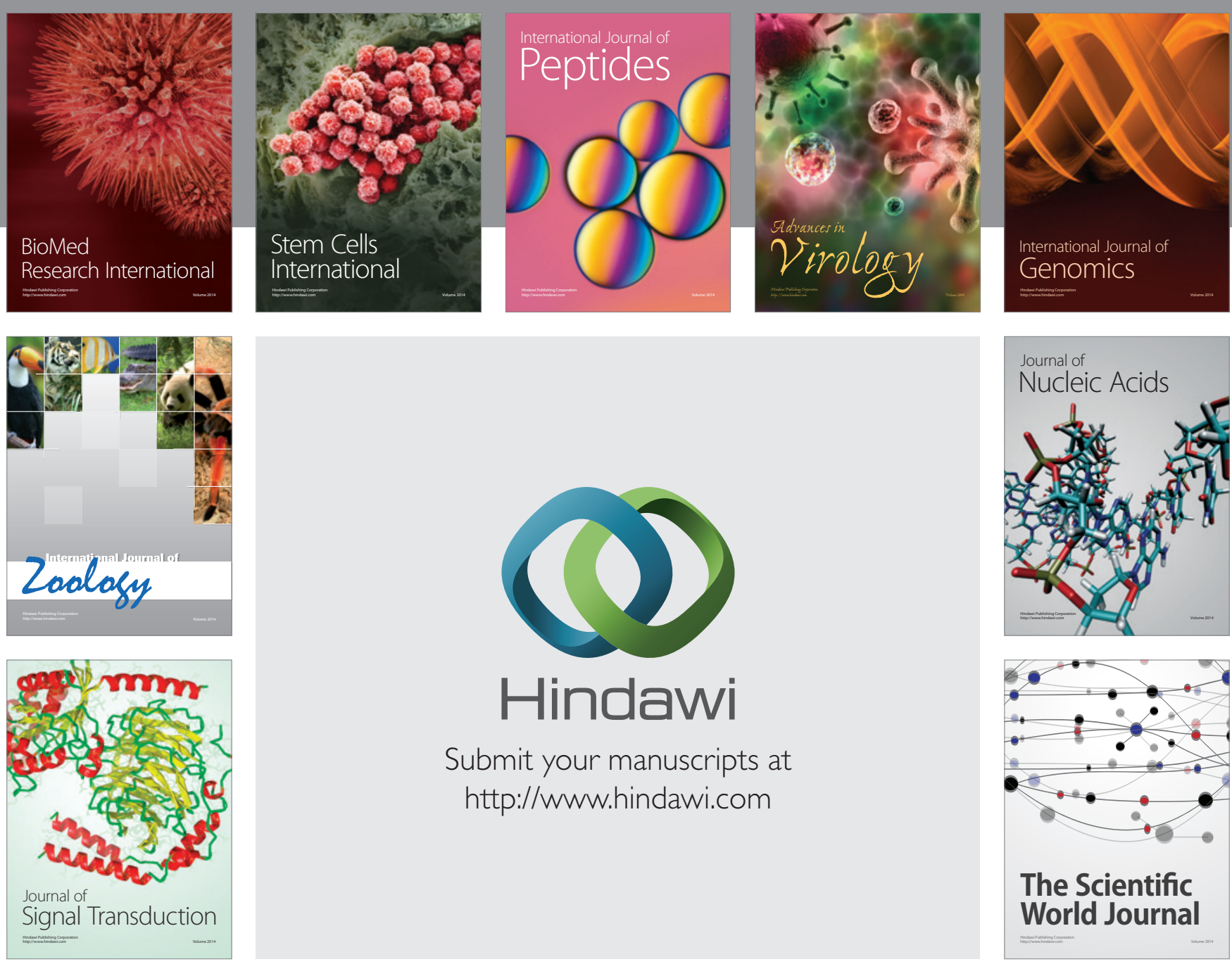

Submit your manuscripts at

http://www.hindawi.com
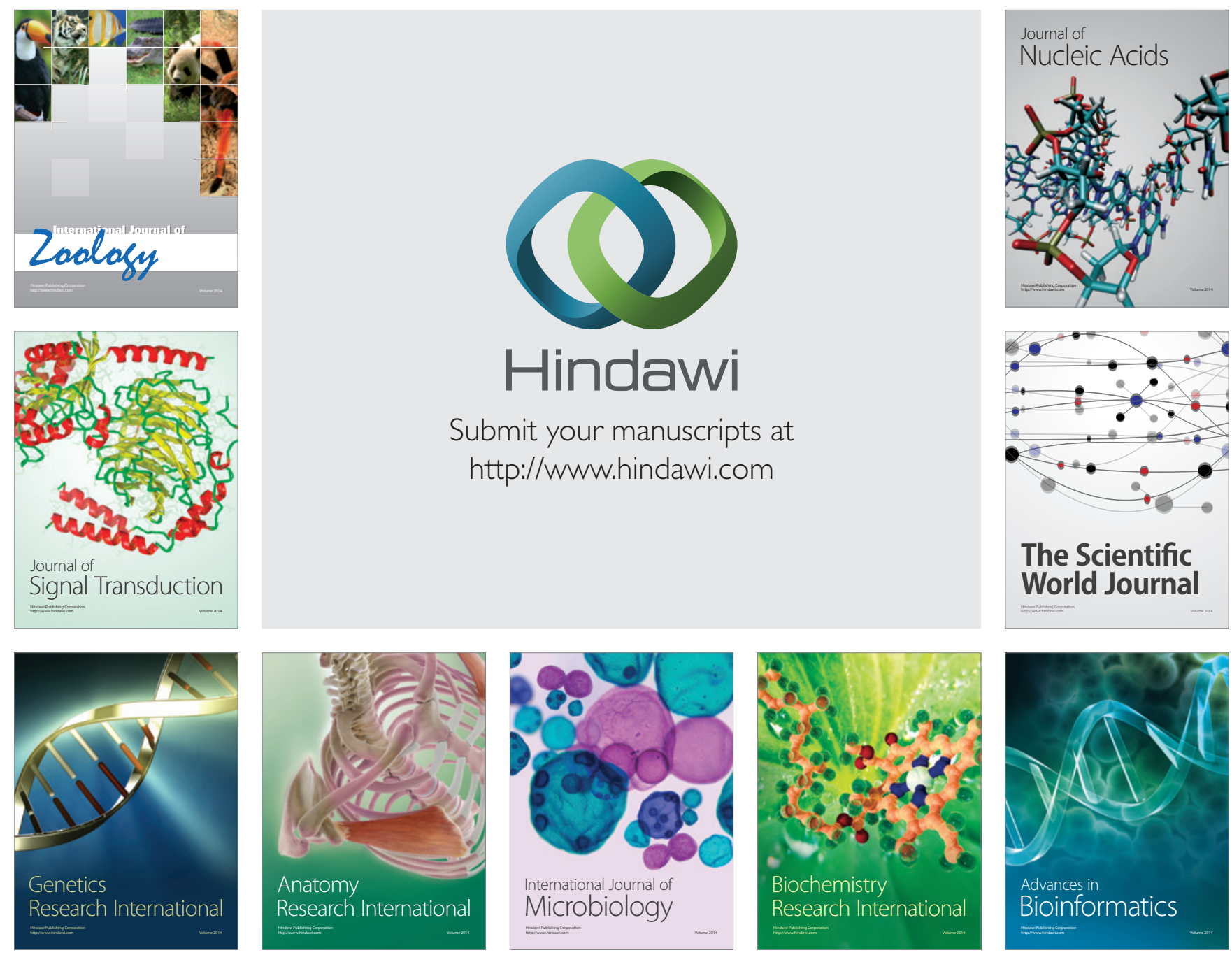

The Scientific World Journal
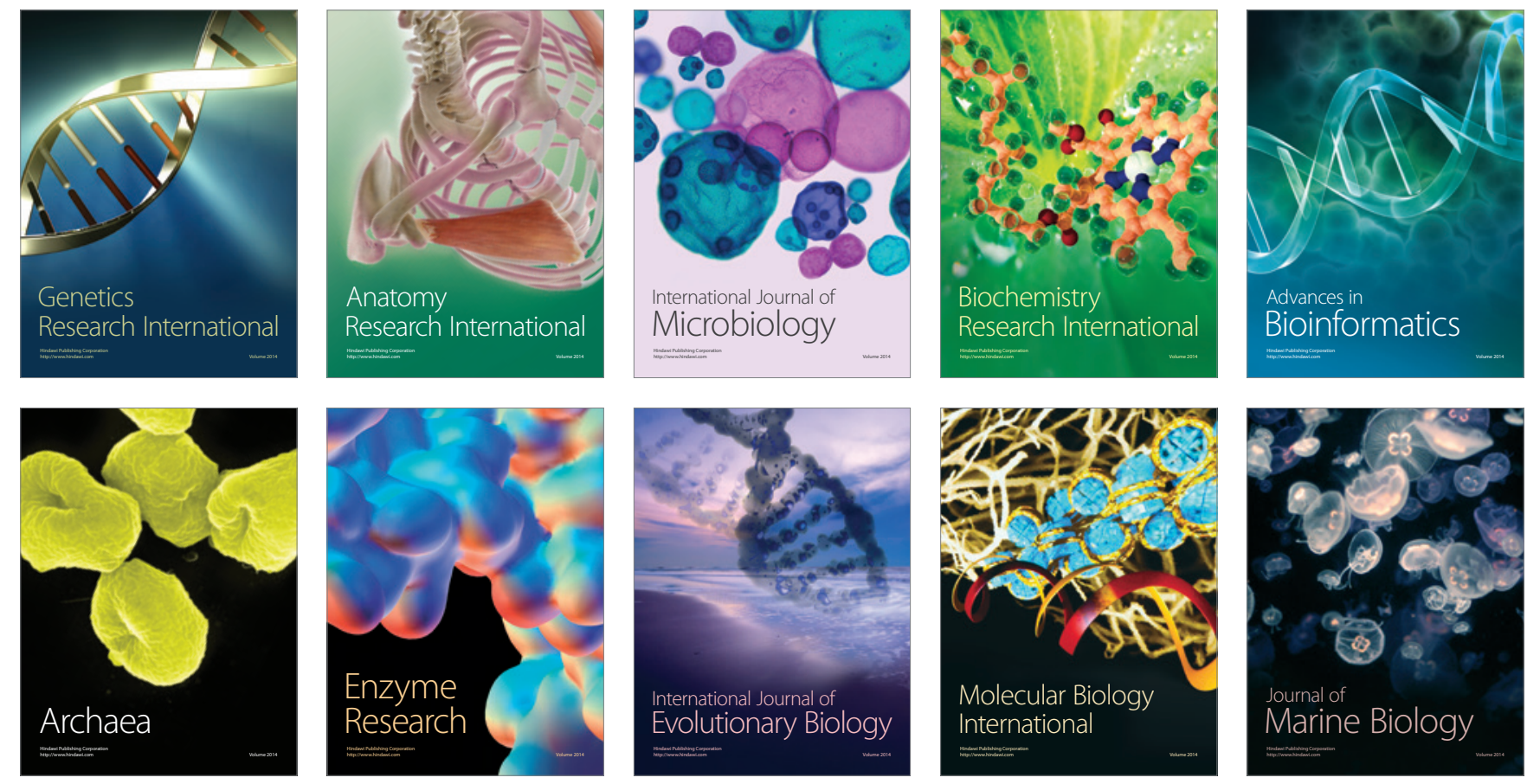